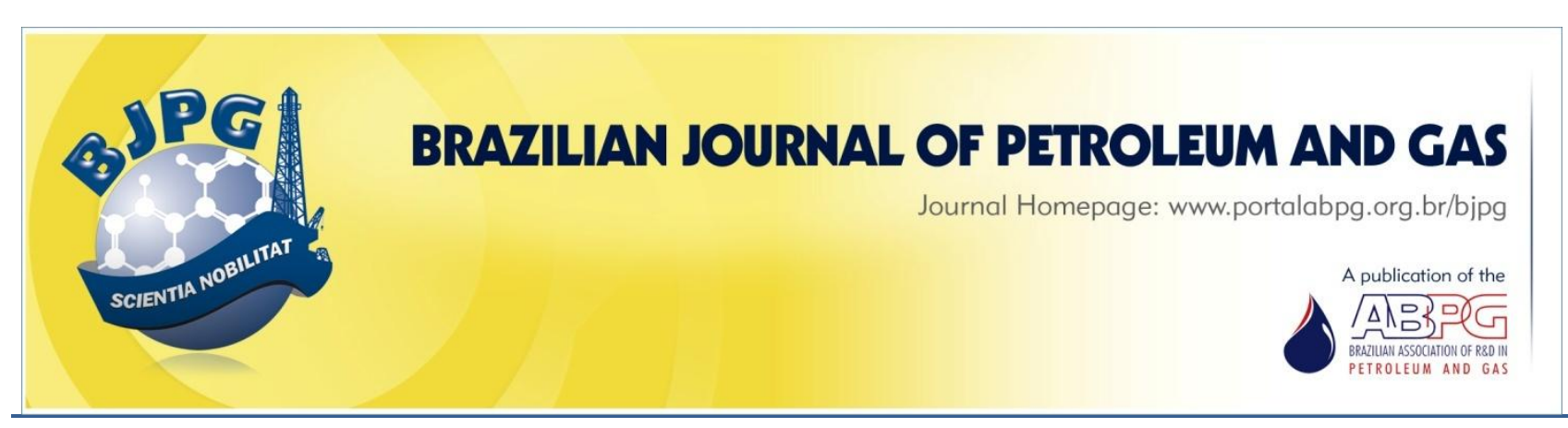

\title{
STRUCTURAL RELIABILITY APPLIED TO ANALYTICAL MODELING OF THE TENSILE STRENGTH OF STANDARD API CASING CONNECTIONS
}

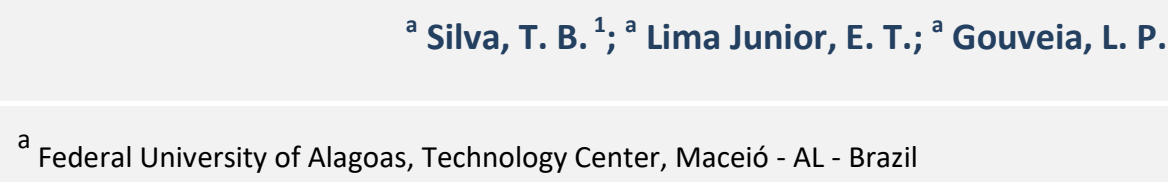

Received: 25.09.2019 / Revised: 11.11.2019 / Accepted: 15.11.2019 / Published on line: 20.12.2019

\begin{abstract}
In oil and gas wells scenario, casing design is a crucial stage of the project, representing the major structural elements responsible for maintaining well integrity through its lifetime and allowing adequate production activities. The occurrence of failures in casing systems can lead to irreversible safety problems in well operation. It is estimated that between $85 \%$ to $95 \%$ of the failures in well tubulars are related to joints (Payne et al., 2006). This work aims to analyze mechanical models of API casing connections in a probabilistic framework. The formulation for evaluating the strength of tubulars, under various load conditions, is presented by the code API TR 5C3 (2008), widely used by oil and gas companies worldwide. The reliability analysis is performed by the Monte Carlo simulation and First Order Reliability Method (FORM), considering failure modes by fracture in round and buttress connections, beyond failures by pullout in round connections.
\end{abstract}

\section{KEYWORDS}

structural reliability; connections; well casing design; tensile strength; OCTG

\footnotetext{
${ }^{1}$ To whom all correspondence should be addressed.

Address: Federal University of Alagoas, Technology Center, Campus AC Simões, Av. Lourival Melo Mota, S/N, Tabuleiro do Martins, Maceió, Alagoas, Brazil.

ZIP Code: 57072-970 | Phone number: +55 (82) 99911-1945 | e-mail: thiago.barbosa@lccv.ufal.br doi:10.5419/bjpg2019-0025
} 


\section{INTRODUCTION}

Advances in science and technology have given rise to a great impetus in the diverse industrial sectors. Consequently, these changes have promoted a considerable demand for increasingly complex structures, which require greater knowledge of the safety levels for which they are designed. Therefore, the incorporation of the uncertainties present in structural design can be performed based on structural reliability theory. In structures, the uncertainties commonly observed and considered are dimensional variability, loads, and mechanical properties of materials.

In this context, according to Melchers and Beck (2018), the theory of structural reliability allows quantifying the uncertainties and calculating the probability of failure of violation of a structural limit state, being either a serviceability limit sate or an ultimate one. According to the authors, reliability is the degree of confidence (subjective probability) that a system will not fail within a specified period and that its operating conditions are respected. Also, the authors define reliabilitycomplementary event, that is, the probability of failure, as the (subjective) probability that the system will fail to meet design specifications.

In the scope of well design, casing design is a crucial step, considering its important functions related to structural support and hydraulic isolation - thus, enabling their operation and production. According to Payne et al. (2006), the connection elements are fundamental in casing system performance, since between $85 \%$ and $95 \%$ of all tubular failures in oil fields are related to connections.

Several studies on the probabilistic performance of Oil Country Tubular Goods (OCTG) have been conducted in recent years. Uribe et al. (2019) presented a numerical study of casing connections subject to make-up torque and tensile axial loads by using finite element models. Zhanghua et al. (2004) investigated the problem of jump-out failure, reporting a better performance of buttress connections compared to round thread ones. Liao et al. (2012) address the probability of casing tubes failure, via Monte Carlo simulation, based on both Klever-Stewart and Klever-Tamano strength models. Gao et al. (2019) evaluated the probabilistic response of casing strings subject to seismic actions by conducting a spectral modal analysis.

This work aims to develop reliability models for the analysis of the tensile strength of standard API connections, based on a normative document widely applied by oil and gas operators (API TR $5 C 3,2008)$. The analyses are performed using Monte Carlo simulation and First Order Reliability Method (FORM) to compare its accuracy and computational cost.

\section{METHODOLOGY}

\subsection{Tensile strength models of standard API Connections}

As stated earlier, normative document API TR 5C3 (2008) defines the equations for the usual failure modes in API connections. The strength equations are calculated with the minimum properties of the steel grade used in pipe body and connection, neglecting the possible presence of internal and external pressures, and considering only axial force. Additionally, depending on the coupling conditions, the connection strength may be lower than that of the pipe body. The specifications for the geometry of casing connections are defined by API 5B (2008), which include three types of connections: round thread, buttress, and extreme-line. The difference between them is the form of the thread element. Extreme line connections will not be addressed in this paper.

The most common type of round connection has eight threads per inch and a V-shaped profile slightly rounded. It can be classified according to engagement length as short thread (STC) or long thread (LC). This type of thread is designed to provide a good seal along the flank. Thread geometry details are shown in Figure 1.

The geometry of buttress connections is trapezoidal, containing 5 threads per inch. Its shape provides high resistance to axial forces (tensile or compressive). Similar to round thread connections, there is a seal between the root of the pin and the crest of the box. The geometry of buttress connections is presented in Figure 2. Due 


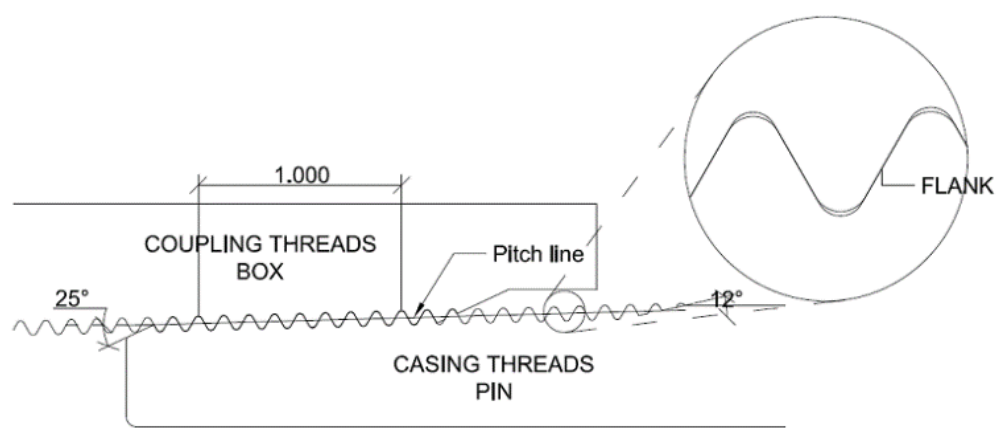

Figure 1. Casing round thread geometry (Cabral, 2014).

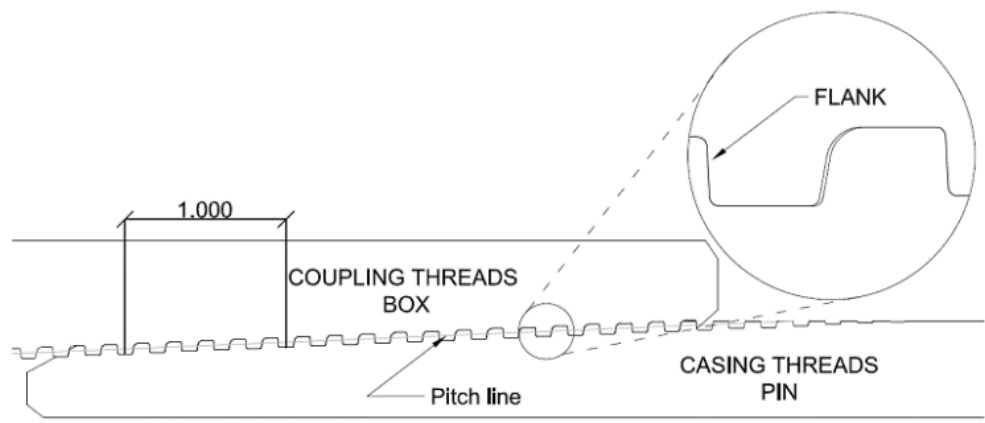

Figure 2. Casing buttress thread geometry (Cabral, 2014).

to the unavoidable thread cutting process, there is a helical leaking path in both connections. Furthermore, it should be noted that buttress connections have greater applicability, in practice, than well casing design. The tensile joint strength of round and buttress connections shown in API TR 5C3 (2008) will be discussed in the following paragraphs.

In round casing connections, the models presented consider fracture of the pipe threads, the pull-out, and the fracture of the coupling. Therefore, round thread casing joint strength is the smallest among the three modes:

$P_{j}=0.95 A_{j p} U_{p}$

(pipe body fracture strength)

$P_{j}=0.95 A_{j p} L\left[\frac{0.74 D^{-0.59} U_{p}}{0.5 L+0.14 D}+\frac{Y_{p}}{L+0.14 D}\right]$

(2) $D$ is the specified outside diameter of the pipe

(pull-out strength)
$P_{j}=0.95 A_{j c} U_{c}$

(coupling fracture strength)

Where:

$P_{j}$ is the joint strength, in pounds;

$A_{j p}$ is the area of the pipe cross section under the last perfect thread, in square inches;

$A_{j c}$ is the is the area of the coupling cross section, in square inches;

$U_{p}$ is the specified minimum tensile strength of the pipe body, in psi;

$U_{c}$ is the specified minimum tensile strength of the coupling, in psi;

$Y_{p}$ is the specified minimum yield strength of the pipe body, in psi;

body, in inches;

$L$ is the engaged thread length, in accordance with API 5B (2008), in inches. 
The pipe thread fracture for the buttress casing connection is given by Equation (4), while the fracture of the coupling is obtained with the same parameters used for the round connection, except for the $A_{j c}$ parameter, which depends on the connection type.

$P_{j}=0.95 A_{p} U_{p}\left[1.008-0.0396\left(1.083-\frac{Y_{p}}{U_{p}}\right) D\right]$

(pipe thread strength)

In the formulation presented, we highlight the presence of factor 0.95 , which corresponds to a reduction factor used in design practice. Such equations, originally in their limit state versions, do not carry the factor. This coefficient ensures a more conservative design condition and it is a simple way to address the uncertainties inherent to the problem.

\subsection{Reliability models for API casing connections}

Reliability models can be performed based on the evaluation of the uncertainties of the design variables, which are statistically described as random variables (r.v.). An important step in the analysis of the theoretical basis of the structural reliability is the statistical characterization, which, in synthesis, is the characterization of a data set (statistical inference) and its representation by a distribution model, supported by goodness-of-fit tests, which assess the quality of the adjustment between the sample data and a candidate statistical model. For more details, see Ang and Tang (2007).

To quantify the failure modes of a structure we used the so-called limit state equations (failure functions), which are deduced from the physical aspects of the problem. Commonly, the failure function is represented by $G(\boldsymbol{X})=0$, where $\boldsymbol{X}$ is a vector containing the $n$ random variables considered in the analysis. For each failure mode of a structure its function establishes a boundary between failure and non-failure regions as follows:

$\left\{\begin{array}{l}G(\boldsymbol{X})>0 \Rightarrow \text { safe event } \\ G(\boldsymbol{X}) \leq 0 \Rightarrow \text { failure event }\end{array}\right.$

This defines the boundaries between the failure $\Omega_{f}$ and survival $\Omega_{s}$ domains of the structure. Failure domain $\Omega_{f}$ is the set of all $\boldsymbol{X}$ points that lead to the failure of the structure, and the safe domain is complementary to it. In any problem, the failure probability is calculated by integrating the joint probability density function of the problem variables over the failure domain, as presented below.

$P_{f}=\int_{\Omega_{f}} f_{X}(\boldsymbol{X}) d x$

The analytical evaluation of this $n$-dimensional integral is not trivial, so it is necessary to use reliability methods for their resolution. In this paper, two methods are addressed: First Order Reliability Method (FORM) and Monte Carlo simulation.

The FORM is based on the transformation of the original random variables (r.v.) into equivalent normal ones. It also promotes the linearization of the failure function. The main advantage of the method lies in its ability to use all the statistical information of the r.v., dealing with any statistical distributions, including correlation between pairs of variables. The reliability problem is formulated as a constrained nonlinear optimization problem, which is iteratively solved by the HLRF algorithm. Further details about the method are presented in Melchers and Beck (2018).

In the Monte Carlo simulation, random numbers are generated to emulate the behavior of true r.v., producing $N$ realizations of the failure function $G(\boldsymbol{X})$, where the events that have negative values, i.e. failure events, are accounted in the variable $\left(N_{f}\right)$. Therefore, the probability of failure is estimated by the ratio between the number of failure events and the total number of realizations, i.e.,

$P_{f}=\frac{N_{f}}{N}$

The random variables used in the reliability analyses are $Y_{p}, U_{p}, U_{c}, D$ (previously defined), coupling outside diameter $(W)$ and pipe wall thickness $(t)$. Three steel grades, usually applied in casing design, are adopted: J55, N80, and P110, which have a minimum yield strength of 55000 psi, 80000 psi, and 110000 psi, respectively.

The statistical information on the variables was obtained based on the manufacturing data published in API TR 5C3 (2008) and on the work 
Table 1. Statistical coefficients used to characterize random variables.

\begin{tabular}{cccccc}
\hline Random variables & & Unit & Nominal & mean & COV \\
\hline Pipe outside diameter $(D)$ & & & 10.75 & 1.0059 & 0.00181 \\
Pipe wall thickness $(\mathrm{t})$ & & in & 0.797 & 1.0069 & 0.0259 \\
Coupling outside diameter $(W)$ & & & 11.75 & 1.00 & 0.0034 \\
\hline \multirow{2}{*}{ Yield strength of the pipe body $\left(Y_{p}\right)$} & $\mathrm{J} 55$ & & 55000 & 1.23 & 0.0719 \\
& $\mathrm{~N} 80$ & psi & 80000 & 1.21 & 0.0405 \\
& $\mathrm{P} 110$ & & 110000 & 1.10 & 0.036 \\
\hline & $\mathrm{J} 55$ & & 75000 & 1.3841 & 0.0675 \\
Tensile strength of the pipe body $\left(U_{p}\right)$ & $\mathrm{N} 80$ & psi & 100000 & 1.1581 & 0.0634 \\
& $\mathrm{P} 110$ & & 125000 & 1.1130 & 0.0566 \\
\hline & $\mathrm{J} 55$ & & 75000 & 1.4241 & 0.0522 \\
& $\mathrm{~N} 80$ & psi & 100000 & 1.2290 & 0.0338 \\
& $\mathrm{P} 110$ & & 125000 & 1.13336 & 0.0161 \\
\hline
\end{tabular}

developed by Clinedinst (1965), an author who has worked extensively on strength models for tubes and connections.

The statistical parameters (mean and standard deviation) of each r.v. are written in terms of mean and COV coefficients, as shown in Table 1 . The mean value of the random variable is obtained by multiplying the factor presented in the table by its nominal value. Regarding the standard deviation, it is obtained by multiplying its mean value by the coefficient of variation (COV). All random variables follow the normal distribution.

\section{RESULTS E DISCUSSIONS}

The probabilistic analyses are performed by adopting a casing tube defined as P110 10 3/4" 85.3 $\mathrm{lb} / \mathrm{ft}$, widely used in intermediate and production casing columns. The objective is to verify the probability of API TR 5 C3 (2008) design strength $\left(R_{\text {rel }}\right)$, in which the r.v. are considered, be exceeded by a solicitation equal to its deterministic value $\left(R_{d e t}\right)$. Therefore, the influence of the consideration of random variables on the formulation proposed in API TR 5C3 (2008) can be verified.

Three limit state equations, defined below, are created for round casing connections, corresponding to models of fracture of the pipe thread (Eq. 8), the pull-out (Eq. 9), and the fracture of the coupling (Eq. 10).

$G\left(U_{p}, D, t\right)=R_{r e l}\left(U_{p}, D, t\right)-R_{\text {det }}$

$G\left(Y_{p}, U_{p}, D, t\right)=R_{r e l}\left(Y_{p}, U_{p}, D, t\right)-R_{\text {det }}$

$G\left(U_{c}, W\right)=R_{r e l}\left(U_{c}, W\right)-R_{d e t}$

The limit state equations for buttress casing connections correspond to fracture of the pipe thread and fracture of the coupling, once buttress connections do not have a pull-out failure. Considering the expression for fracture of the coupling is identical for round connections, the failure function is the same as shown in Equation (10). In the case of fracture of the pipe thread, the limit state function is defined in terms of such random variables, being identical to Equation (8).

In the failure functions variable $R_{\text {det }}$ represents the deterministic resistance, calculated directly from the API 5C3 formulation, and $R_{\text {rel }}$ represents the probabilistic resistance calculated with the limit state formulation, taking into account the randomness of the design variables. 
Table 2. Failure probability for round thread casing connection resistance models.

\begin{tabular}{ccccccc}
\hline & \multicolumn{3}{c}{ FORM } & \multicolumn{2}{c}{ Monte Carlo } \\
\cline { 2 - 6 } Steel grades & fracture (pipe) & pull-out & fracture (coupling) & fracture (pipe) & pull-out & fracture (coupling) \\
& & & & & & \\
\hline J55 & $2.004 \mathrm{E}-06$ & $3.993 \mathrm{E}-06$ & $1.7498 \mathrm{E}-09$ & $2.667 \mathrm{E}-06$ & $3.96 \mathrm{E}-06$ & - \\
N80 & $2.250 \mathrm{E}-03$ & $9.101 \mathrm{E}-08$ & $4.011 \mathrm{E}-08$ & $2.298 \mathrm{E}-03$ & - & - \\
P110 & $4.870 \mathrm{E}-03$ & $7.560 \mathrm{E}-05$ & $3.879 \mathrm{E}-07$ & $4.999 \mathrm{E}-03$ & $8.035 \mathrm{E}-05$ & - \\
\hline
\end{tabular}

Table 3. Failure probability for buttress thread casing connection resistance models.

\begin{tabular}{ccccc}
\hline \multirow{2}{*}{$\begin{array}{c}\text { Steel } \\
\text { grades }\end{array}$} & $\begin{array}{c}\text { fracture } \\
\text { (pipe) }\end{array}$ & $\begin{array}{c}\text { fracture } \\
\text { (coupling) }\end{array}$ & $\begin{array}{c}\text { fracture } \\
\text { (pipe) }\end{array}$ & $\begin{array}{c}\text { fracture } \\
\text { (coupling) }\end{array}$ \\
\cline { 2 - 5 } & $2.705 \mathrm{E}-08$ & $6.152 \mathrm{E}-09$ & $5.715 \mathrm{E}-08$ & - \\
J55 & $5.198 \mathrm{E}-06$ & $4.345 \mathrm{E}-07$ & $5.52 \mathrm{E}-06$ & - \\
P110 & $1.57 \mathrm{E}-04$ & $1.508 \mathrm{E}-05$ & $1.615 \mathrm{E}-04$ & $1.544 \mathrm{E}-05$ \\
\hline
\end{tabular}

Using the FORM transformation method and Monte Carlo simulation, we estimated the value of $P_{f}$ for each failure mode mentioned, as shown in Tables 2 and 3.

As noted in the tables presented, failure probability values obtained for both connections using the FORM and Monte Carlo methods are congruent, validating the implementations developed in this work. It is noticed that Monte Carlo simulation has limitations to find very low $P_{f}$ values, due to the need to perform a large number of simulations, which considerably increases the computational cost.

The dominant failure mode in both round and buttress connections is the fracture of the pipe threads, presenting the highest $P_{f}$ values for the three steel grades considered; except for grade J55 in round connections, which is associated to the highest $P_{f}$ value due to pull-out. P110 steel provides the critical values of probability of failure, while the results for the 155 steel stand out as being the smallest $P_{f}$ ones. One aspect on the statistical parameters that explains the good performance of J55 products is the average value, which is between $23 \%$ and $42 \%$ higher than the nominal value, even though the dispersion level is also significant in some cases, see Table 1 .

\section{CONCLUSIONS}

The incorporation of design variables uncertainties through structural reliability allowed us to evaluate the safety levels associated with the formulation proposed by normative document API TR 5C3 (2008). It is noteworthy that the connection design formulation presented in this code is the one effectively adopted in sizing practice around the world, being the same as the one presented in the previous version of the code (API Bull 5C3, 1999).

The results presented are only indicative of the probabilistic behavior of the resistances, considering that the random variables were characterized based on manufacturing data published in API TR 5C3 (2008) and the work developed by Clinedinst (1965). The reliabilitybased approach can be replicated in the analysis of oil well casing design if pipe and connection production statistics are available from a specific manufacturer.

Structural reliability analyses were performed using two methods. The robustness of the FORM transformation method was evident when compared to the Monte Carlo simulation. However, due to the low complexity of the Monte Carlo 
computational implementation, this can be an interesting option for a first estimate of the probability of failure.

Studies as the presented herein are expected to contribute to the dissemination of the probabilistic design philosophy applied to oil well casing. API TR 5C3 (2008) already suggests probabilistic procedures for assessing pipe resistance to internal pressure and collapse, in informative annexes.

\section{ACKNOWLEDGMENTS}

The authors of the present study would like to acknowledge Petróleo Brasileiro (PETROBRAS) for the financial support provided.

\section{REFERENCES}

Ang, A.; Tang, W. Probability concepts in engineering planning and design: Emphasis on application to civil and environmental engineering. New York: Wiley, 2007.

API BULL 5C3. Bulletin on formulas and calculations for casing, tubing, drill pipe and line pipe properties. Washington: American Petroleum Institute, 1999.

API 5B. Specification for Threading, Gauging and Thread Inspection of Casing, Tubing and Line Pipe Threads. Washington: American Petroleum Institute, 2008.

API TR 5C3. Technical Report on Equations and Calculations for Casing, Tubing, and Line Pipe Used as Casing or Tubing; and Performance Properties Tables for Casing and Tubing. Washington: American Petroleum Institute, 2008.
Cabral, C. P. Análise da Resistência de Conexões em Revestimentos de Poços. Relatório Final de Projeto de Pesquisa, Universidade Federal de Alagoas, Maceió, 2014. (in portuguese)

Clinedinst, W. O. Strength of threaded joints for steel pipe. Journal of Engineering for Industry, v. 87, n. 2, p. 125-134, 1965.

https://doi.org/10.1115/1.3670774

Gao, J.; Shi, W.; Cui, S.; Jiao, Y. Reliability analysis for seismic capacity of casing strings. Journal of Petroleum Exploration and Production Technology, p. 1-6, 2019.

https://doi.org/10.1007/s13202-019-00765-8

Liao, H.; Guan, Z.; Long, G. Quantitative risk assessment on safety and reliability of casing strength for oil and gas wells. Energy Procedia, v. 17, p. 429-435, 2012.

https://doi.org/10.1016/i.egypro.2012.02.116

Melchers, R. E.; Beck, A. T. Structural reliability analysis and prediction. John Wiley \& Sons, 2018. https://doi.org/10.1002/9781119266105

Payne, M.; Schwind, B.; Park, J.; Coker, O.; Wu, J.; Postler, D.; Comet, A. Project aims to qualify tubular connections. Drilling contractor, v. 62, n. 3, p. 60-62, 2006.

Uribe, J. C. M; Carrazedo, R.; Beck, A. T. Leakage Resistance Envelopes of API 8 Round Casing Connections using FE Analysis. Latin American Journal of Solids and Structures, v. 16, n. 3, 2019. https://doi.org/10.1590/1679-78255350

Zhanghua, L.; Yonggang, L; Bo, T. Analysis of Jump-Out Loads about Connectors of Buttress and Round Threads of Casing. China Petroleum Machinery, v. 5, p. 7, 2004. 